\title{
High gender -specific susceptibility to curare- a neuromuscular blocking agent
}

\author{
Santosh K. Maurya, Muthu Periasamy ${ }^{1}$ and Naresh C. Bal ${ }^{2}$ \\ 1 Davis Heart and Lung Research Institute, Ohio State University, Columbus, Ohio, USA \\ 2 Department of Physiology and Cell Biology, The Ohio State University, College of Medicine, Columbus, OH 43210, United States.
}

\begin{abstract}
Curare, a selective skeletal muscle relaxant, has been used clinically to reduce shivering and as an anesthetic auxiliary in abdominal surgery. It is also widely used in animal experiments to block neuromuscular junction activity. Effective doses of curare diminish muscle contraction without affecting brain function, but at higher doses it is known to be lethal. However, the exact dose of curare initiating muscle relaxation $v s$. lethal effect has not been fully characterized in mice. In this study we carefully examined the dose-response for achieving muscle inactivity over lethality in both male and female mice (C57BL6/J). The most striking finding of this study is that female mice were highly susceptible to curare; both the $\mathrm{ED}_{50}$ and $\mathrm{LD}_{50}$ were at least 3-fold lower than male littermates. This study shows that gender-specific differences can be an important factor when administering skeletal muscle relaxants, particularly curare or other analogous agents targeted to the neuromuscular junction.
\end{abstract}

Key terms. Curare, dose response, gender, muscle activity, oxygen consumption.

\section{INTRODUCTION}

Curare has long been used by the Indians of South America as an arrow poison for hunting wild game (Bisset, 1992). After it became known that curare affects voluntary muscles selectively without affecting the brain and heart it was widely used in modern medicine as an auxiliary in general anesthesia, frequently with cyclopropane (Anderson, 2010; Lee, 2003). Curare has recently been used in humans to reduce shivering (Hovland et al., 2006), and is also used in animal experimentation to block shivering (Hovland et al., 2006; Kashimura et al., 1992; Nonogaki et al., 1991), to diagnose myasthenia gravis (a muscle disease) (Biesecker and Koffler, 1988; Somnier and Trojaborg, 1993) and to manipulate neurosysnaptic transmission (Witoonpanich et al., 1989) etc. Curare acts as a neuromuscular blocking agent by binding to the acetylcholine receptor (AChR) at the neuromuscular junction and preventing nerve impulses from activating skeletal muscles (Bowman, 2006). Although high doses of curare are lethal, low doses are well tolerated and the effect is completely reversible (Clement, 1978). However, it is not known if curare has a gender-specific effect on physical activity and whole body metabolic rate. In this study we therefore examined the dose-dependent effects of curare on both male and female mice littermates by monitoring physical activity, core body temperature (Tc), whole animal oxygen consumption, circadian rhythm and feeding behavior.

\section{METHODS}

Experimental Animals: Age-matched (12-18 weeks old) male and female mice (C57BL/6J) littermates were housed at a temperature of $22 \pm 1{ }^{\circ} \mathrm{C}$ with a 12:12-h light: dark cycle and relative humidity about 50\%. Diet (2014, Harlan Teklad) and water was provided ad libitum. The study protocol was approved by the Ohio State University Institutional Animal Care and Use Committee. All of the animal procedures were carried out at our AAALAC-accredited animal facility and conducted in accordance with the Guide for the Care and Use of Laboratory Animals.

Curare dose response: Tubocurarine hydrochloride (curare with better solubility profile) was purchased from SigmaAldrich, St. Louis, MO. Curare solution ( $0.9 \% \mathrm{NaCl}$ solution) was administered intraperitonially in various quantities as reported in Table $\mathbf{1}$. The mice were individually monitored for at least 30 minutes after treatment for drug effect. Dose and percentage of death were fitted into a dose-response graph in GraphPad Prism 3.0 software to calculate the $\mathrm{LD}_{50}$ (dose at which $50 \%$ of the mice died). From the dose-response curves an effective sub-lethal dose $\left(\mathrm{ED}_{\mathrm{i}}\right)$, at which mice became immobile for few minutes, was determined for both male and female mice.

Monitoring of circadian rhythm and basal metabolic rate (BMR): To determine if administration of curare affects the metabolic rate in male and female mice differently, we measured oxygen consumption $\left(\mathrm{VO}_{2}\right)$, RER (respiratory exchange ratio) and physical activity (measured by infrared sensors installed around each housing cage). These experiments were performed at $25 \pm 1.0{ }^{\circ} \mathrm{C}$ using a Comprehensive Lab Animal Monitoring System (oxymax/CLAMS) equipped with a temperature-controlled environmental chamber from Columbus Instruments, Columbus, $\mathrm{OH}$, USA. The mice were given $\mathrm{ED}_{\mathrm{i}}$ at 10AM following 18 hours acclimatization at $25 \pm 1.0{ }^{\circ} \mathrm{C}$ and metabolic measurements were recorded.

Core body Temperature measurement in mice exposed to cold: Core body temperature (Tc) was measured by thermal transponders (IPTT300, Bio Medic Data System, Seaford, $\mathrm{DE})$. Mice were administered with $\mathrm{ED}_{\mathrm{i}}$ of curare and allowed to recover for 30 minutes and then challenged with $4{ }^{\circ} \mathrm{C}$. Tc, oxygen consumption and physical activity were continuously monitored using oxymax/ CLAMS. 
TABLE 1

Dose-dependent effect of curare (tubocurarine) on male and female mice

\begin{tabular}{|c|c|c|c|c|c|c|}
\hline \multirow{2}{*}{ Dose (mg/kg) } & \multicolumn{3}{|c|}{ Female } & \multicolumn{3}{|c|}{ Male } \\
\hline & Total animals tested & Mortality & Immobility & Total animals tested & Mortality & Immobility \\
\hline 0.04 & 10 & 0 & 0 & 10 & 0 & 0 \\
\hline 0.05 & 10 & 0 & 0 & 10 & 0 & 0 \\
\hline 0.06 & 10 & 0 & 3 & 10 & 0 & 0 \\
\hline 0.08 & 11 & 0 & 4 & 10 & 0 & 0 \\
\hline 0.1 & 10 & 2 & 7 & 10 & 0 & 0 \\
\hline 0.2 & 11 & 5 & 11 & 10 & 0 & 1 \\
\hline 0.3 & 10 & 6 & 10 & 10 & 0 & 3 \\
\hline 0.4 & 11 & 9 & 11 & 10 & 2 & 6 \\
\hline 0.5 & 10 & 9 & 10 & 7 & 2 & 6 \\
\hline 0.6 & 10 & 10 & 10 & 8 & 5 & 8 \\
\hline 0.8 & & & & 10 & 8 & 10 \\
\hline 1 & & & & 9 & 9 & 9 \\
\hline
\end{tabular}

Statistical analysis: Mortality data were analyzed using student't' test (nonparametric) using Graph pad Prism software and $p<0.05$ was considered significant.

\section{RESULTS}

We were interested in studying the role of muscle shivering over non-shivering thermogenic (NST) mechanisms contributing to heat production and Tc maintenance (Bal et al., 2012). Therefore we chose to utilize curare, which has been shown to reduce shivering (Hovland et al., 2006; Kashimura et al., 1992). We first set out to optimize the dose that would minimize shivering by using different doses of curare in both male and female mice. Interestingly, the $\mathrm{LD}_{50}$ of curare for the female mice was very low $(0.22 \mathrm{mg} / \mathrm{kg})$ as compared to male mice $(0.75$ $\mathrm{mg} / \mathrm{kg}$ ) (Figure $1 \mathrm{~A}$ ). At doses below $\mathrm{LD}_{50}$, curare completely immobilizes the mice for 10 minutes, after which mice can be used for experimental studies with maximal inhibition of shivering for the next $\sim 5$ hours. The $\mathrm{ED}_{50}$ for achieving complete immobility was calculated to be $0.38 \mathrm{mg} / \mathrm{kg}$ for males, while that for the female mice was $0.01 \mathrm{mg} / \mathrm{kg}$ (Figure 1A). The difference in percentage mortality between male and female groups was found to be statistically significant by applying a student't' test $(p=0.003)$. The number of animals used in this study for each dose of curare and number of animals affected is presented in Table 1. These data suggest that females are highly susceptible to curare and one-third dose for males is sufficient to achieve complete immobility. Therefore, for all the remaining studies reported here, we chose $0.4 \mathrm{mg} / \mathrm{kg}$ for male and $0.1 \mathrm{mg} /$ $\mathrm{kg}$ for female mice as their respective effective dose to achieve immobility $\left(\mathrm{ED}_{\mathrm{i}}\right)$. The immobility induced at these doses $(0.4$ $\mathrm{mg} / \mathrm{kg}$ for male and $0.1 \mathrm{mg} / \mathrm{kg}$ for female mice) was completely reversible within $\sim 10$ minutes.

Administration of curare causes an immediate effect on physical activity and mice are immobilized for a short period. Therefore, we studied if curare has a long-lasting effect on metabolism (measured as whole body $\mathrm{O}_{2}$ consumption) and physical activity on both male and female mice. $\mathrm{O}_{2}$ consumption remained unchanged regardless of gender and dose administered $\left(E_{i}\right)$. Following curare $\left(E D_{i}\right)$ administration, physical activity remained low for $\sim 3$ hours both in males (Figure 2A) and in females (Figure 2B). Other parameters, including $\mathrm{Tc}$, respiratory exchange ratio (RER or respiratory quotient), energy expenditure measured at $25 \pm 1^{\circ} \mathrm{C}$ did not show any significant difference (Supplemental Figure). At $\mathrm{ED}_{\mathrm{i}^{\prime}}$ both male and female mice were able to tolerate the acute cold challenge of $4{ }^{\circ} \mathrm{C}$ (maintained Tc around $37.0^{\circ} \mathrm{C}$ ) and were able to upregulate their metabolism to meet the thermogenic demands during cold stress, which is reflected in the increase in $\mathrm{O}_{2}$ consumption (Figure 2C and 2D).

\section{DISCUSSION}

Curare has been used as a muscle relaxant in clinical surgery until recently, when safer alternatives became available. Many of these newer muscle relaxants have similar chemical structures/moieties and also have an analogous mode of action through AChR (Bowman, 2006). Although widely used as a muscle relaxant in clinical surgery, gender-specific differences have not been reported previously. However, it was recently administered in a female patient to reduce shivering (Hovland et al., 2006) and one report suggested that female patients should receive a lower dose of curare (Bennett, 1968), indicating that gender-specific differences may exist. This is the first study to report that female mice are more sensitive to curare at a concentration three fold $\left(\mathrm{LD}_{50}\right)$ lower than males, but the exact mechanism is unclear. We used reproductively mature mice; the reproductive cycle of the female mice and their hormonal status were not considered. However, we expect that there is very little chance of overlap between the reproductive cycles of the 103 female mice used in the present study. Therefore, the role of reproductive hormones in the observed sensitivity of female mice to curare can be ruled out. This difference between males and females might 

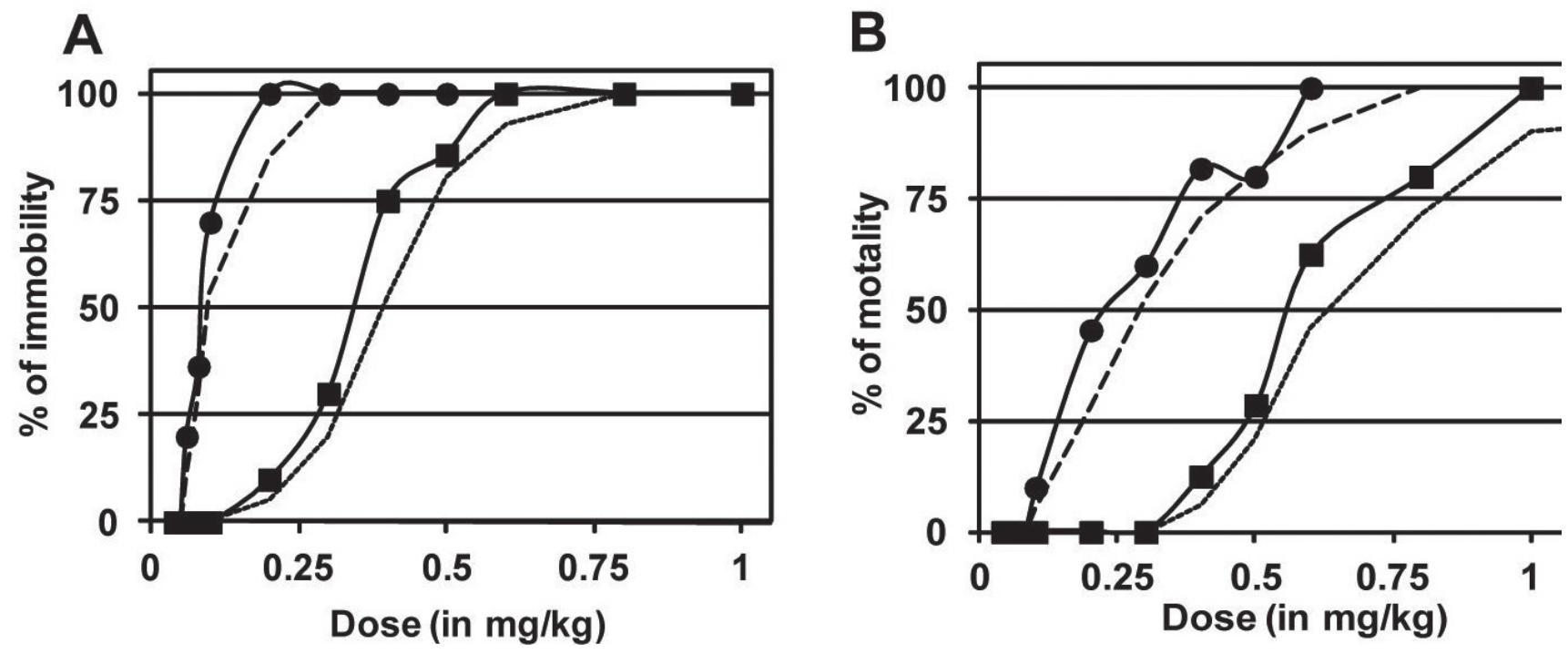

Figure 1: Comparison of curare dose response for male vs. female mice. (A) Immobility curve and (B) survival curve. Solid circles represent female mice and solid squares are the male mice. Dashed and dotted lines are the trend lines for females and males, respectively.
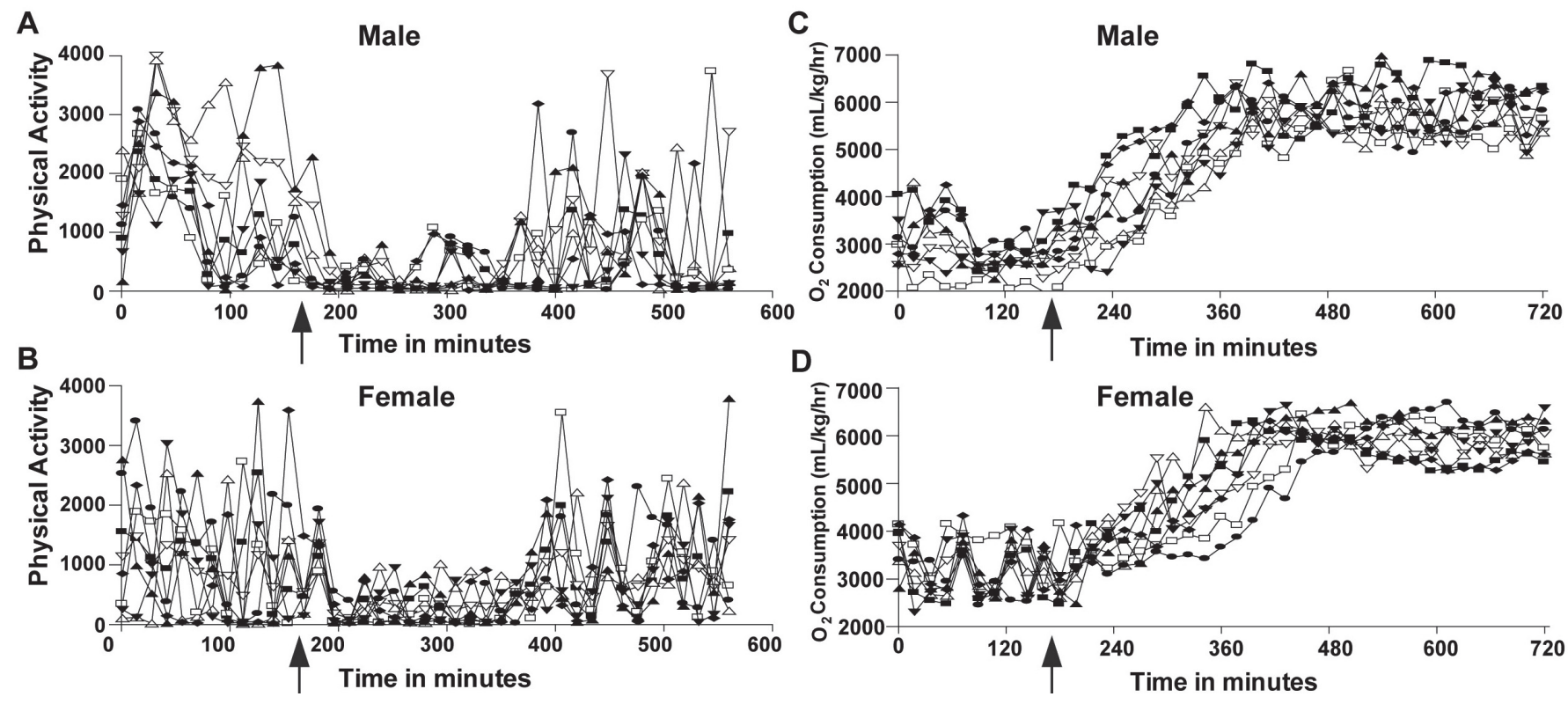

Figure 2: Physiological and metabolic effects of curare. Effect on physical activity of male mice (A) and physical activity of female mice (B) at $25 \pm 1.0^{\circ} \mathrm{C}$. Effect on $\mathrm{VO}_{2}$ in male mice (C) and female mice (D) upon acute cold challenge. Individual data on 8 male and female mice are presented. The time of administration of curare is indicated by arrows. In C and $\mathbf{D}$ the cold challenge was started 30 minutes after curare administration.

be due to intrinsic gender-specific differences in recruitment and activation of neuromuscular junctions (Green et al., 1984; Simoneau et al., 1985) and/or gender-specific differences in ability of clearance of the drug from the body. Although the rate of metabolic clearance of curare in mice is not known, clearance for another plant-derived alkaloid, strychnine, has been reported to be slower in female mice, which may be the basis of higher sensitivity of female mice towards these alkaloids (Durkin, 2010). Another interesting finding of this study is that the $\mathrm{ED}_{50}$ and $\mathrm{LD}_{50}$ for curare are close. Therefore, the curare dose for a given experiment should be chosen carefully to avoid lethality-induced differential results. Our study highlights the importance of a gender-specific difference in the curare doseresponse relationship. Therefore it calls for careful reevaluation of dose response in females before administering muscle relaxants including curare-like molecules.

\section{ACKNOWLEDGEMENTS}

This work was supported in part by National Institutes of Health Grant R01 HL64014 to M. P. N.C.B. was supported by a postdoctoral fellowship from the American Heart Association. 


\section{REFERENCES}

ANDERSON R. (2010). A TORTURED PATH: Curare's Journey from Poison Darts to Paralysis by Design. Mol Interventions 10:252-258.

BAL NC, MAURYA SK, SOPARIWALA DH, SAHOO SK, GUPTA SC, SHAIKH SA, PANT M, ROWLAND LA, BOMBARDIER E, GOONASEKERA SA, TUPLING AR, MOLKENTIN JD, PERIASAMY M. (2012). Sarcolipin is a newly identified regulator of muscle-based thermogenesis in mammals. Nat Med 18:1575-9.

BENNETT AE. (1968). The history of the introduction of curare into medicine. Anesth Analg 47:484-92.

BIESECKER G, KOFFLER D. (1988). Resistance to experimental autoimmune myasthenia gravis in genetically inbred rats. Association with decreased amounts of in situ acetylcholine receptor-antibody complexes. J Immunol 140:3406-10.

BISSET NG. (1992). War and hunting poisons of the New World. Part 1. Notes on the early history of curare. J Ethnopharmacol 36:1-26.

BOWMAN WC. (2006). Neuromuscular block. Br J Pharmacol 147:S277-86.

CLEMENT JG. (1978). Effect of ethanol, pentobarbital and morphine on the toxicity of hemicholinium-3 and d-tubocurarine in mice. Arch Int Pharmacodyn Ther 236:60-5.

DURKIN PR. (2010). Strychnine: Human Health and Ecological Risk Assessment. USDA/Forest Service, Southern Region, 1720 Peachtree RD, NW Atlanta, Georgia 30309
GREEN HJ, FRASER IG, RANNEY DA. (1984). Male and female differences in enzyme activities of energy metabolism in vastus lateralis muscle. J Neurol Sci 65:323-31.

HOVLAND A, NIELSEN EW, KLUVER J, SALVESEN R. (2006). EEG should be performed during induced hypothermia. Resuscitation 68:143-6.

KASHIMURA O, SAKAI A, YANAGIDAIRA Y, UEDA G. (1992), Thermogenesis induced by inhibition of shivering during cold exposure in exercise-trained rats. Aviat Space Environ Med 63:1082-6.

LEE C. (2003). Conformation, action, and mechanism of action of neuromuscular blocking muscle relaxants. Pharmacol Ther 98:143-69.

NONOGAKI K, IGUCHI A, YATOMI A, UEMURA K, MIURA H, TAMAGAWA T, ISHIGURO T, SAKAMOTO N. (1991). Dissociation of hyperthermic and hyperglycemic effects of central prostaglandin F2 alpha. Prostaglandins 41:451-62.

SIMONEAU JA, LORTIE G, BOULAY MR, THIBAULT MC, THERIAULT G, BOUCHARD C. (1985). Skeletal muscle histochemical and biochemical characteristics in sedentary male and female subjects. Can J Physiol Pharmacol 63:30-5.

SOMNIER FE, TROJABORG W. (1993). Neurophysiological evaluation in myasthenia gravis. A comprehensive study of a complete patient population. Electroencephalogr Clin Neurophysiol 89:73-87.

WITOONPANICH R, VEJJAJIVA A, LIMPISVASTI S. (1989). Regional curare test in the study of neuromuscular transmission in hyperthyroidism. J Med Assoc Thai 72:187-91. 